\title{
Deficiency in Endocannabinoid Signaling in the Nucleus Accumbens Induced by Chronic Unpredictable Stress
}

\author{
Wei Wang ',3, Dalong Sun ${ }^{1,2,3}$, Bin Pan', Christopher J Roberts', Xinglai Sun', Cecilia J Hillard' and \\ Qing-song Liu*,I \\ 'Department of Pharmacology and Toxicology, Medical College of Wisconsin, Milwaukee, WI, USA; ${ }^{2}$ Department of Geriatrics, Shandong \\ University, Qilu Hospital, Jinan, People's Republic of China
}

\begin{abstract}
The nucleus accumbens (NAc) is a critical component of the reward circuitry, and dysfunction of the NAc may account for anhedonia and other symptoms of depression. Here, we investigated whether alterations in endocannabinoid (eCB) signaling in the NAc contribute to depression-like behaviors induced by chronic unpredictable stress (CUS) in mice. We compared three types of eCB/CBI receptormediated synaptic plasticity in slices prepared from the NAc core of control and stress-exposed mice: depolarization-induced suppression of excitation, long-term depression, and the depression of field excitatory postsynaptic potentials (fEPSPs) induced by group I metabotropic glutamate receptor agonist DHPG. CUS (5-6-week exposure to stressors), but not sub-CUS (I week exposure to stressors), induces depression-like behaviors and impairs these forms of eCB/CBI receptor-mediated plasticity examined in the NAc core. Neither sub-CUS nor CUS altered the tissue contents of the eCBs, anandamide and 2-arachidonoylglycerol in the striatum. However, exposure to CUS, but not to sub-CUS, attenuated the depression of fEPSPs induced by the CBI receptor agonist WIN 552 12-2. CUS exposure reduced the maximal effect without affecting the $\mathrm{EC}_{50}$ of WIN $55212-2$ to induce fEPSP depression. Thus, impaired CBI receptor function could account for CUS-induced deficiency in eCB signaling in the NAc. Both CUS-induced deficiency in eCB signaling and depression-like behaviors were reversed by in vivo administration of antidepressant fluoxetine. These results suggest that downregulation of eCB signaling in the NAc occurs after CUS and contributes to the pathophysiology of depression. Neuropsychopharmacology (2010) 35, 2249-2261; doi:I0.1038/npp.2010.99; published online 21 July 2010
\end{abstract}

Keywords: chronic unpredictable stress; endocannabinoid; CBI receptor; DSE; nucleus accumbens; depression

\section{INTRODUCTION}

The endocannabinoid (eCB) system regulates mood, emotion, motivation, appetite, body weight, and cognition, while anhedonia, lack of motivation, poor appetite, weight loss, and impairment of cognitive function are common features of depression (Mangieri and Piomelli, 2007; Gorzalka et al, 2008; Hill et al, 2009; Lutz, 2009). CB1 agonists and inhibitors of eCB degradation produce anxiolytic- and antidepressant-like effects in animal models of anxiety and depression (Berrendero and Maldonado, 2002; Valjent et al, 2002; Gobbi et al, 2005; Jiang et al, 2005; Patel and Hillard, 2006; Bortolato et al, 2007). Conversely, CB1 receptor antagonists SR141716 (rimonabant) and AM251 produce anxiogenic-like effects in rodents (Navarro et al, 1997; Haller et al, 2004; Rodgers et al, 2005), and rimonabant

\footnotetext{
*Correspondence: Dr Qing-song Liu, Department of Pharmacology and Toxicology, Medical College of Wisconsin, 870I Watertown Plank Road, Milwaukee, WI 53226, USA. Tel: + |-4|4-456-8877,

Fax: + |-4|4-456-6545, E-mail: qsliu@mcw.edu

${ }^{3}$ These authors contributed equally to this work.

Received 28 April 2010; accepted 16 June 2010
}

increases the incidence of anxiety and depression in clinical trials for the treatment of obesity (Samat et al, 2008). These studies suggest that the eCB system has an important role in the pathophysiology of depression.

The mechanism by which the $\mathrm{eCB}$ system regulates emotional homeostasis remains poorly understood. An attractive hypothesis is that the eCB system is disturbed and downregulated in anxiety and depression, and enhanced CB1 receptor activation can compensate for the deficiency in $\mathrm{eCB}$ signaling and therefore 'normalize' mood and emotion. Previous studies have shown that the tissue content of eCBs and/or $\mathrm{CB} 1$ receptor binding site density are decreased in a number of brain regions in chronic unpredictable stress (CUS) model of depression (Hill et al, 2005, 2008a; Bortolato et al, 2007). Although these biochemical approaches provide a general assessment of the quantity of eCB ligands and CB1 receptors, they do not interrogate the functional consequences of these changes on CB1 receptor-mediated signaling. In addition, these approaches do not have sufficient temporal and spatial resolution to capture the dynamic nature of $e C B / C B 1$ signaling. Measurement of eCB/CB1 receptor-mediated physiological responses in slices taken from animals 
exposed to 'depressogenic' stimuli is a methodological approach that could overcome these limitations.

A primary function of eCBs is to mediate short- and longterm synaptic depression (Alger, 2005; Heifets and Castillo, 2009; Kano et al, 2009). Several forms of eCB/CB1 receptormediated synaptic depression have been described previously. First, depolarization-induced $\mathrm{Ca}^{2+}$ influx triggers the production of eCBs, which activate $\mathrm{CB} 1$ receptors to induce transient suppression of excitatory or inhibitory synaptic transmission (referred as DSE and DSI, respectively; Pitler and Alger, 1992; Kreitzer and Regehr, 2001; Ohno-Shosaku et al, 2001; Wilson and Nicoll, 2001). Second, the CB1 receptor mediates a form of long-term depression (LTD) in a number of brain regions, including the dorsal striatum and NAc (Gerdeman et al, 2002; Robbe et al, 2002; Heifets and Castillo, 2009). Third, the group I metabotropic glutamate receptor (mGluR) agonist, DHPG, induces $\mathrm{CB} 1$ receptor-dependent synaptic depression (Maejima et al, 2001; Varma et al, 2001; Robbe et al, 2002). In addition to these endogenous cannabinoidmediated responses, the CB1 receptor agonist WIN 55212 2 induces acute depression of the synaptic transmission. Recording these four types of CB1 receptor-mediated physiological responses provides a good measure of the ongoing status of eCB signaling.

The nucleus accumbens (NAc) is an important anatomical substrate for motivation and reward, and dysfunction of the NAc could account for anhedonia, decreased sex drive, social withdrawal, and other symptoms of depression (Nestler and Carlezon, 2006). The NAc expresses relatively high levels of CB1 receptors (Herkenham et al, 1991; Robbe et al, 2001; Pickel et al, 2004). Given the role of the eCB system in mood regulation (Hill et al, 2009; Lutz, 2009), alterations of $\mathrm{eCB}$ signaling might occur in the NAc in depression. In the present study, we examined whether the aforementioned CB1 receptor-mediated responses were altered in the NAc in CUS model of depression. We report herein that CUS-induced deficiency in $\mathrm{eCB} / \mathrm{CB} 1$ receptormediated responses in the NAc slices ex vivo, which was reversed by chronic administration of the antidepressant fluoxetine. These results have identified abnormalities in eCB signaling in the NAc in an animal model of depression.

\section{MATERIALS AND METHODS}

\section{Animals}

Male C57BL/6J mice (8-10 weeks of age) were purchased from the Jackson Laboratory and were allowed to habituate for 1 week. Animals were maintained in a temperature$\left(23 \pm 1^{\circ} \mathrm{C}\right)$ and humidity-controlled room (40-60\%). Unless otherwise specified, the animals were given ad libitum access to food and water, and housed on a 12-h light-dark cycle with lights switched on at 0700 hours. Animal maintenance and use were in accordance with protocols approved by the Institutional Animal Care and Use Committee of the Medical College of Wisconsin.

\section{Chronic Unpredictable Stress}

A CUS paradigm was used as an animal model of depression on the basis of well-established methods with minor modifications (Willner et al, 1987; Koo and Duman, 2008). After 1 week of initial habituation and 1 week of training to drink a sucrose solution (see 'sucrose-intake test'), mice were subjected to various and repeated unpredictable mild stressors for a period of 1 week (sub-CUS) or 5-6 weeks (CUS). In experiments in which fluoxetine was chronically administered, CUS was extended to 8 weeks. The stressors included inversion of day/night light cycle, $45^{\circ}$ tilted cage $(12 \mathrm{~h})$, restraint $(20 \mathrm{~min}$ in a soft, flexible plastic cone, DecapiCone, MDC-200, Braintree Scientific), predator sounds (20 $\mathrm{min})$, low-intensity stroboscopic illumination (in dark $12 \mathrm{~h}, 10 \mathrm{~Hz}$ ), food and water deprivation (overnight), cage rotation (20 $\mathrm{min}$ ), cold environment (in a cold room at $4^{\circ} \mathrm{C}$ for $1 \mathrm{~h}$ ), wet bedding $(250 \mathrm{ml}$ water added into the cage), and no bedding. During the course of each experimental week, 14-18 stressors were administered (Supplementary Tables S1 and S2). For stressed animals, cages were changed after 'wet bedding' and 'no bedding' stressors. Unstressed controls were handled only for weight and other behavioral measurements (see below), injections, and for changing the cage (twice weekly).

\section{Behavior}

The schedule of the behavioral tests is described in Supplementary Table S3.

Sucrose-intake test. After 1 week of habituation, mice were trained to drink a sucrose solution. Mice were exposed to two drinking bottles for 1 week. One bottle contained $1 \%$ sucrose (in tap water) and the other contained tap water. The baseline sucrose intake was established, and mice were divided into two groups with matched sucrose intake, one group of mice was exposed to CUS and the other group served as non-stressed control. For sucrose-intake test, control and CUS-exposed mice were deprived of food and water for $8 \mathrm{~h}$ (1000-1800 hours), and then exposed to the sucrose solution and water from 1800 hours to 1000 hours next day. Both absolute and relative sucrose intakes (absolute sucrose intake/body weight) were measured.

Open-field test. Mice were placed individually in one corner of the open field $(50 \mathrm{~cm}$ long $\times 45 \mathrm{~cm}$ wide $\times 30 \mathrm{~cm}$ deep box) and allowed to freely explore the arena during a 15-min test session. Locomotor activities were recorded using an automated video-tracking system (Mobile Datum, Shanghai, China). Total distance traveled and time spent in the center of the box during a 5-min session were calculated. Time in the center is defined as the amount of time that was spent in the central $25 \times 22.5 \mathrm{~cm}^{2}$ area of the open field.

Forced swim test. Mice were placed individually in the glass cylinders ( $13 \mathrm{~cm}$ diameter, $25 \mathrm{~cm}$ height) filled to a depth of $18 \mathrm{~cm}$ with water $\left(25 \pm 1^{\circ} \mathrm{C}\right)$. The mice were placed in the cylinders for a 6-min pre-exposure. After $24 \mathrm{~h}$, a second 6-min swim test session was videotaped and the time spent being immobile during the last $4 \mathrm{~min}$ was scored by an observer blind to treatment conditions. Immobility was defined as the cessation of all movements (eg, climbing and swimming) except those necessary for the mouse to keep its head above water (ie, floating). 
Novelty-suppressed feeding (NSF). NSF was carried out similar to a published protocol (Santarelli et al, 2003). Mice were deprived of food for $48 \mathrm{~h}$ before being placed for $5 \mathrm{~min}$ in a novel environment (a plastic box $45 \mathrm{~cm}$ long $\times 35 \mathrm{~cm}$ wide $\times 20 \mathrm{~cm}$ deep), where a single food pellet (regular chow) was placed on a piece of white filter paper $(11 \mathrm{~cm}$ in diameter) in the center of the box. An animal was placed in one corner of the box, and the latency to feed was measured. Feeding was defined as biting the food using forepaws and not simply sniffing or touching the food (Supplementary Videos S1 and S2). Immediately after the test, the animal was transferred to the home cage, and the latency to feed in the home cage was measured to serve as controls.

Drug injections. Fluoxetine (Sigma) was dissolved in saline solution $(0.9 \% \mathrm{NaCl})$ and was injected i.p. daily $(10 \mathrm{mg}$ per $\mathrm{kg}$ body weight in a volume of $10 \mu \mathrm{l}$ per g body weight) for 4 weeks. The same volume of saline was injected i.p. to serve as controls.

\section{Slice Preparation}

Control and stress-exposed mice were anesthetized by isoflurane inhalation and were decapitated. Striatal slices containing the NAc $(250 \mu \mathrm{m}$ thick) were prepared as described in our previous studies (Pan et al, 2008a,b). The slices were immediately transferred and incubated in artificial cerebrospinal fluid (ACSF) containing $125 \mathrm{mM}$ $\mathrm{NaCl}, 3 \mathrm{mM} \mathrm{KCl}, 2.5 \mathrm{mM} \mathrm{CaCl}, 1 \mathrm{mM} \mathrm{MgCl}, 1.25 \mathrm{mM}$ $\mathrm{NaH}_{2} \mathrm{PO}_{4}, 26 \mathrm{mM} \mathrm{NaHCO}_{3}$, and $10 \mathrm{mM}$ glucose. The ACSF was saturated with $95 \% \mathrm{O}_{2}$ and $5 \% \mathrm{CO}_{2}$. Slices were recovered for at least $1 \mathrm{~h}$ at room temperature before recordings.

\section{Electrophysiology}

Whole-cell patch-clamp and extracellular field potential recordings were performed in the core of the NAc, the area immediately surrounding the anterior commissure (Paxinos and Watson, 1986). Excitatory postsynaptic currents (EPSCs) or field excitatory postsynaptic potentials (fEPSPs) were evoked by a bipolar tungsten stimulation electrode (WPI) that was placed 300-500 $\mu \mathrm{m}$ away from the recording pipette. Stimuli were delivered by a Master-8 stimulator with an isolation unit (AMPI). The recordings were made using a patch-clamp amplifier, Multiclamp 700B, under infrared-differential interference contrast microscopy. For recording the evoked EPSCs, glass pipettes (4-6 M $)$ ) were filled with an internal solution containing $135 \mathrm{mM}$ cesium methanesulfonate, $10 \mathrm{mM} \mathrm{CsCl}, 2 \mathrm{mM}$ QX-314, $10 \mathrm{mM}$ HEPES, $0.2 \mathrm{mM}$ EGTA, $2 \mathrm{mM} \mathrm{MgCl}_{2}, 4 \mathrm{mM}$ MgATP, $0.3 \mathrm{mM} \mathrm{Na} \mathrm{N}_{2} \mathrm{GTP}$, and $10 \mathrm{mM} \mathrm{Na}_{2}$-phosphocreatine ( $\mathrm{pH} 7.2$ with $\mathrm{CsOH}$ ). For recording the fEPSPs, glass pipettes (1-2M 2 ) were filled with the ACSF. Signals were filtered at $2 \mathrm{kHz}$ and sampled at $10 \mathrm{kHz}$. All recordings were taken at $32 \pm 1^{\circ} \mathrm{C}$ by using an automatic temperature controller (Warner Instrument, Hamden, CT).

\section{Tissue Collection and Corticosterone Assays}

Control and CUS-exposed mice were anesthetized by isoflurane inhalation and decapitated. Trunk blood was collected between 0830 and 1000 hours, and adrenals and thymus were excised and weighed immediately. Blood samples were centrifuged at $1500 \mathrm{~g}$ for $10 \mathrm{~min}$; serum was removed and stored at $-80^{\circ} \mathrm{C}$ until the assay. Serum corticosterone concentrations were determined by an enzyme-linked immunosorbent assay kit (MP Biomedicals), as previously described (Patel et al, 2004).

\section{Biochemical Detection of Anandamide (AEA) and 2-Arachidonoylglycerol (2-AG)}

Control and stress-exposed mice were anesthetized by isoflurane inhalation and were decapitated. Their brains were removed immediately and frozen on dry ice, and the striatum was dissected. The primary eCBs AEA and 2-AG were extracted from the striatum as previously described (Patel et al, 2003). Briefly, tissue samples were weighed and placed into borosilicate glass culture tubes containing $2 \mathrm{ml}$ of acetonitrile with $8.4 \mathrm{pmol}$ of $\left[{ }^{2} \mathrm{H}_{8}\right] \mathrm{AEA}$ and $23 \mathrm{pmol}$ of $\left[{ }^{2} \mathrm{H}_{8}\right] 2-\mathrm{AG}$ for extraction. They were homogenized and sonicated in an ice-cold water bath for $30 \mathrm{~min}$. Samples were incubated overnight at $-20^{\circ} \mathrm{C}$ to precipitate proteins and subsequently centrifuged at $1500 \mathrm{~g}$ for $3 \mathrm{~min}$. The supernatants were transferred to a new glass tube and evaporated to dryness under $\mathrm{N}_{2}$ gas. The samples were resuspended in $300 \mu \mathrm{l}$ of methanol to recapture any lipids adhering to the glass tube and dried again under $\mathrm{N}_{2}$ gas. Finally, lipid extracts were suspended in $20 \mu \mathrm{l}$ of methanol and stored at $-80^{\circ} \mathrm{C}$ until analysis. AEA and 2-AG tissue contents were determined using isotope-dilution liquid chromatographyelectrospray ionization tandem mass spectrometry.

\section{Data Analysis and Statistics}

All results are expressed as mean \pm SEM. Values of 2-3 DSE trials were averaged for each neuron, and the decay time constant $(\tau)$ and magnitude of DSE were measured as described (Pan et al, 2009). The depression (\%) of fEPSPs by agonists and antagonists, and the magnitude of LTD were determined as described (Pan et al, 2008a,b). Concentration-response curves were obtained using a sigmoidal dose-response equation: $y=$ (maximumminimum $) /\left(1+\left(\mathrm{EC}_{50} / x\right)^{N}\right)$, in which $E_{\max }$ is the maximal response, $x$ is the concentration of the drug, $\mathrm{EC}_{50}$ is the concentration of the drug eliciting half-maximal response, and $N$ is the Hill slope of the concentration-response curve. Data were analyzed using two-way ANOVA followed by Tukey post hoc analysis. Post hoc analyses were performed only when ANOVA yielded a significant main effect or a significant interaction between the two factors. In addition to the two-way ANOVA, we made planned comparisons to test a priori hypotheses and to determine whether the two specific groups were significantly different. Results were considered to be significant at $p<0.05$.

\section{RESULTS}

\section{Characterization of eCB-Mediated DSE and LTD in the NAc}

We characterized the properties of DSE in the NAc core region in striatal slices prepared from control mice. To our 
knowledge, DSE has not been previously described in the NAc. Whole-cell voltage-clamp recordings were made from medium spiny neurons (MSNs), which are GABAergic neurons that make up the vast majority (90-95\%) of cells in the NAc (Meredith, 1999; Zhou et al, 2002). The MSNs were voltage-clamped at $-80 \mathrm{mV}$, close to the resting membrane potential of these neurons (Dehorter et al, 2009). MSNs were identified visually by their medium-sized, spindle-like cell bodies, large initial axon segment, and electrophysiological characteristics (hyperpolarizing membrane potentials immediately after break-in and biexponential decay of capacitive transients; Kreitzer and Malenka, 2005). EPSCs were evoked every $4 \mathrm{~s}$ in the presence of NMDA receptor antagonist AP5 $(50 \mu \mathrm{M})$ and $\mathrm{GABA}_{\mathrm{A}}$ receptor antagonist picrotoxin $(50 \mu \mathrm{M})$. These EPSCs were abolished by $\alpha$-amino-3-hydroxy-5-methyl-4-isoxazole propionic acid (AMPA) receptor antagonist $\mathrm{CNQX}(10 \mu \mathrm{M}, n=3$; data not shown), suggesting that they are mediated by the activation of AMPA receptors. Depolarization steps from -80 to $0 \mathrm{mV}$, with varied durations $(1,5$, and $10 \mathrm{~s})$, did not induce significant depression of EPSCs (Figure 1a). Increasing the depolarization (from -80 to 10 or $20 \mathrm{mV}, 5 \mathrm{~s}$ ) did not induce significant depression of EPSCs either (Figure $1 \mathrm{~b}$ ). These results indicate that depolarization alone is not sufficient to induce significant DSE in the NAc.
Activation of certain G-protein-coupled receptors, including group I mGluRs, facilitates the induction of DSE in the dorsal striatum (Narushima et al, 2006) and DSI in the hippocampus (Edwards et al, 2006). In the continuous presence of the group I mGluR agonist DHPG $(5 \mu \mathrm{M})$, a 5-s depolarization step from -80 to $0 \mathrm{mV}$ induced DSE in the NAc (Figure 1c). DSE induced in the presence of DHPG was abolished by the CB1 receptor antagonist AM $251(2 \mu \mathrm{M}$; Figure 1c), indicating that it is mediated by CB1 receptor activation. This induction protocol (a 5-s depolarization step from -80 to $0 \mathrm{mV}$ in the presence of $5 \mu \mathrm{M}$ DHPG) was used in all subsequent DSE experiments.

eCB signaling mediates not only short-term depression such as DSE and DSI, but also a form of LTD (Heifets and Castillo, 2009). eCB-mediated LTD has been described in the dorsal striatum (Gerdeman et al, 2002) and NAc (Robbe et al, 2002). We used extracellular field recordings of the LTD of fEPSPs in NAc slices, as this recording configuration allows long-term stable recordings in slices prepared from adult mice, as shown in a previous study (Robbe et al, 2002). Baseline fEPSPs were evoked in the core of the NAc by stimulating excitatory afferents at $0.1 \mathrm{~Hz}$. These fEPSPs were abolished by the AMPA receptor antagonist CNQX $(10 \mu \mathrm{M}, n=3$; data not shown), suggesting that they are mediated by the activation of AMPA receptors. Consistent
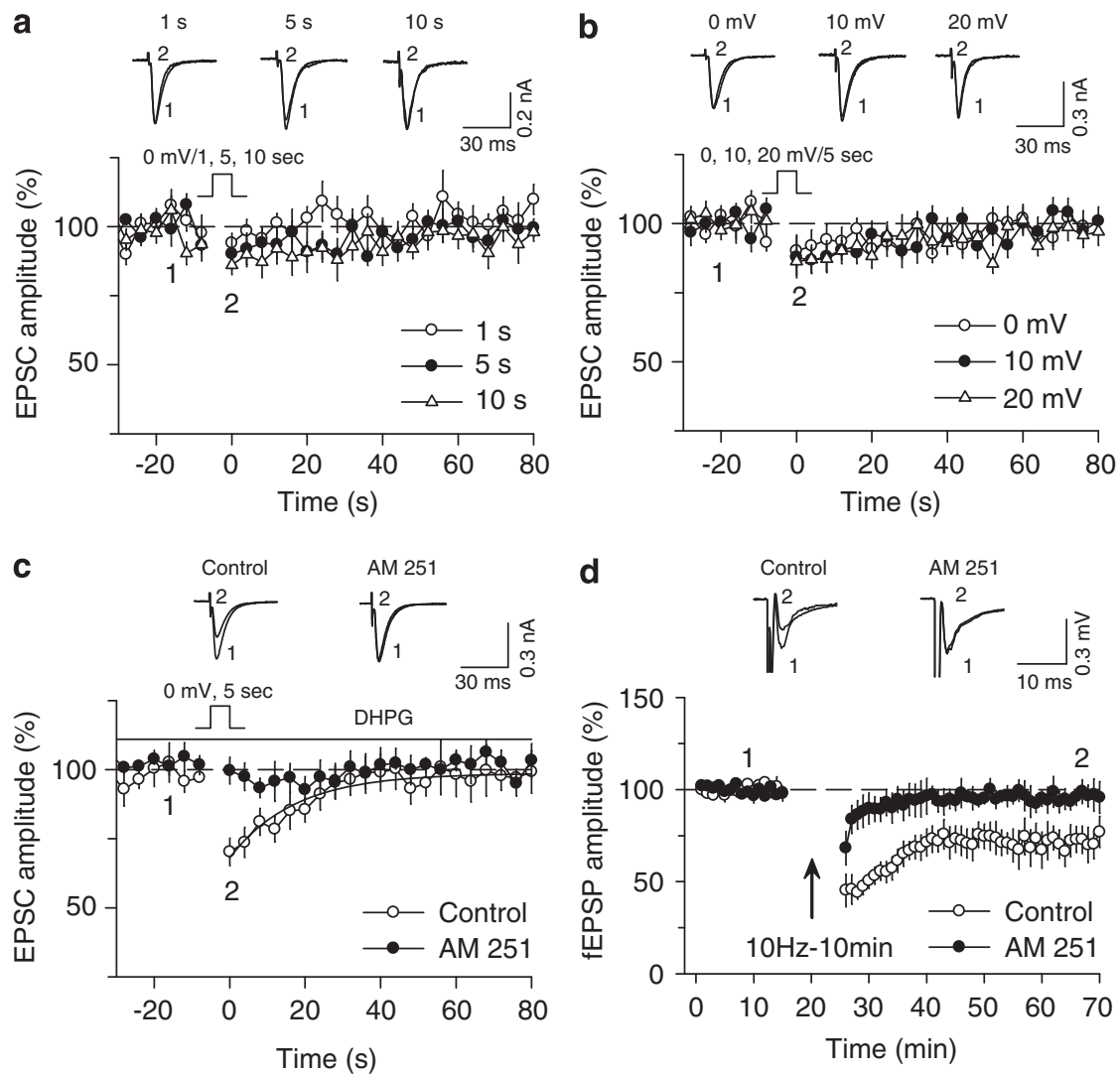

Figure I Characterization of DSE and LTD in the NAc core. (a) Depolarization steps from -80 to $0 \mathrm{mV}$ with varied durations (I, 5, and I0 s) did not induce significant DSE $(n=8-9)$. Top, sample EPSCs in MSNs of the NAc before (indicated by ' 1 ') and $0 \mathrm{~s}$ after (indicated by ' 2 ') the application of various depolarization steps (from -80 to $0 \mathrm{mV} ; \mathrm{I}, 5$, and $10 \mathrm{~s}$ ). (b) Increasing the depolarization (from -80 to 10 or $20 \mathrm{mV} ; 5 \mathrm{~s}$ ) did not induce significant DSE either ( $n=9$ for each group). (c) The presence of DHPG $(5 \mu \mathrm{M})$ enabled a depolarization step (from -80 to $0 \mathrm{mV} ; 5 \mathrm{~s})$ to induce DSE ( $n=8)$. The DSE was abolished by the CBI receptor antagonist $A M 25$ I $(2 \mu \mathrm{M} ; n=6 ; p<0.0$ I vs control). The line superimposed is the single exponential fitting curve of the decay of DSE, which yields $\tau$. (d) The $10 \mathrm{~Hz}, 10$ min stimulation (indicated by arrow) induced LTD $(n=7)$, which was abolished by the CBI receptor antagonist AM 25I ( $2 \mu \mathrm{M} ; n=6 ; p<0.05$ vs LTD control). 
with previous studies (Gerdeman et al, 2002; Robbe et al, 2002), we found that repetitive stimulation of synaptic afferents at moderate frequency $(10 \mathrm{~Hz})$ for $10 \mathrm{~min}$ induced LTD of fEPSPs, which was blocked by AM 251 (Figure 1d).

\section{CUS, but not Sub-CUS, Induces Depression-Like Behaviors}

We have used CUS exposure to induce depression-like behaviors in mice (Willner et al, 1987). Mice were exposed to a variety of mild stressors in an unpredictable manner for 1 week (sub-CUS) or 5-6 weeks (CUS), whereas age-matched control mice did not receive any special treatments except normal handling and behavioral tests. Initial body weights, which were measured after habituation but before stress exposure, were not significantly different among the four groups (main effect stress: $F(1,44)=0.189$, $p>0.05$; main effect time: $\mathrm{F}(1,44)=0.020, \quad p>0.05$; stress $\times$ time interaction: $\mathrm{F}(1,44)=0.034, p>0.05$; Supplementary Figure S1a). However, two-way ANOVA revealed that both stress and time (ie, 1 week or 5-6 weeks) have significant effects on body weight (determined at the time shown in Supplementary Table S3; main effect stress: $\mathrm{F}(1,44)=6.649, p<0.05$; main effect time: $\mathrm{F}(1,44)=6.495$, $p<0.05$; stress $\times$ time interaction: $\mathrm{F}(1,44)=1.903, p>0.05$; Figure 2a). A priori (planned) comparisons were made to test the following possibilities: (1) control groups showed age-dependent increase in body weight and (2) CUS decreased the body weight. The results indicate that there was an age-dependent increase in body weight in control groups (control (for sub-CUS) vs control (for CUS), $p<0.01$ ) and that CUS significantly decreased the body weight (control (for CUS) vs CUS, $p<0.01$; Figure 2a).

Mice exposed to CUS showed significantly decreased sucrose intake, whereas those exposed to sub-CUS were not different from control (main effect stress: $\mathrm{F}(1,44)=7.450$, $p<0.01$; main effect time: $\mathrm{F}(1,44)=9.188, \quad p<0.01$; stress $\times$ time interaction: $\mathrm{F}(1,44)=4.698, p<0.05$; control (for sub-CUS) vs sub-CUS, $p>0.05$; control (for CUS) $v s$ CUS, $p<0.001$; sub-CUS vs CUS, $p<0.001$; Tukey's post hoc test; Figure 2b).

As CUS-exposed mice weighed significantly less than the time-matched control mice (Figure 2a), we also examined the relative sucrose intake, which is normalized to body weight. Both stress and time significantly affected the relative sucrose intake; however, the interaction was not significant (main effect stress: $\mathrm{F}(1,44)=4.099, p<0.05$; main effect time: $\mathrm{F}(1,44)=14.566, p<0.001$; stress $\times$ time interaction: $\mathrm{F}(1,44)=3.547, p>0.05(p=0.066))$. Planned comparisons of the differences between control and CUS groups were carried out, which showed that CUS significantly decreased the relative sucrose intake compared with the control ( $p<0.01$; Figure $2 c)$. In addition, analysis of the Pearson's product-moment correlation coefficient revealed no significant correlation between CUS-induced changes in body weight and absolute sucrose intake (correlation coefficient $r=0.270, p>0.05)$. Neither sub-CUS nor CUS significantly affected water intake (main effect stress: $\mathrm{F}(1,44)=0.061, \quad p>0.05$; main effect time: $\mathrm{F}(1,44)=$ $0.521, p>0.474$; stress $\times$ time interaction: $F(1,44)=0.003$,

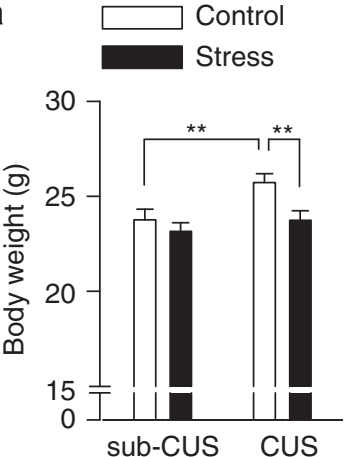

d

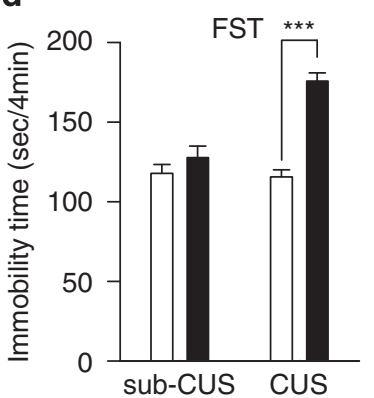

b

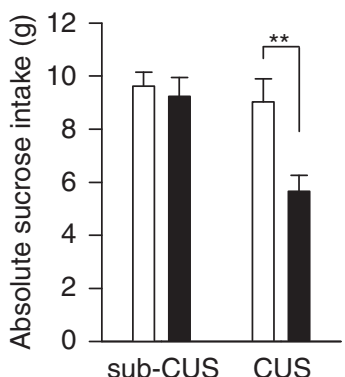

e

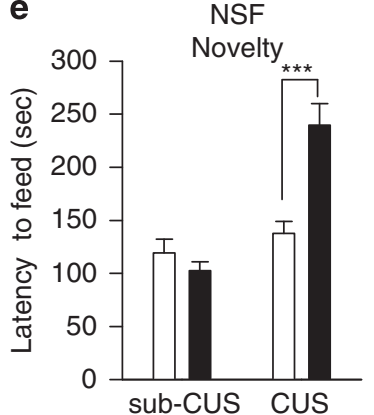

C
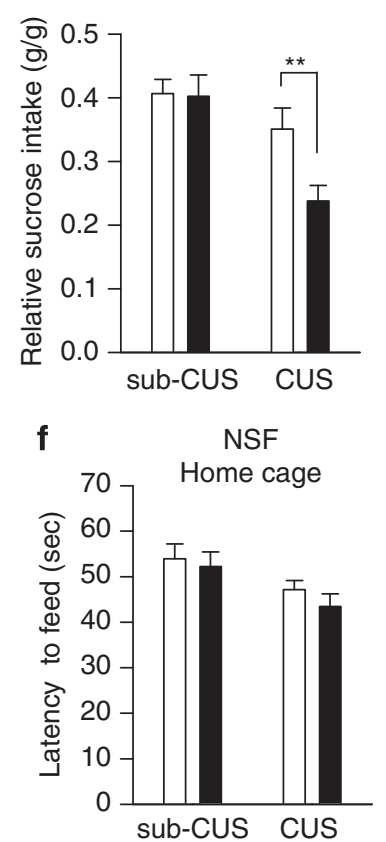

Figure 2 CUS (5-6-week stress), but not sub-CUS (I-week stress), induced depression-like behaviors. (a-c) Compared with time-matched controls, CUS exposure significantly decreased the body weight (a), absolute sucrose intake (b), and relative sucrose intake (c) (** $p<0.0 \mathrm{I})$, whereas sub-CUS had no significant effect on these three parameters $(p>0.05)$. (d) Compared with time-matched controls, CUS, but not sub-CUS, significantly increased the immobility time in the FST $(* * * * 60.00 \mathrm{I}$ ). (e, f) In NSF test, CUS exposure significantly increased the latency to feed in the novel environment $(* * * 0.00$ I) (e), but did not affect the latency to feed in the home cage $(p>0.05 ; f)$. 
$p>0.05$; Supplementary Figure S1b). Thus, it is likely that CUS-induced anhedonia, not the loss of body weight, accounts for the decrease in sucrose intake.

We used an open-field test to determine whether CUSexposed mice show abnormalities in locomotor activity and anxiety-related behavior. Mice tend to avoid open spaces when exposed to an open-field arena. Reduced activity in the center of an open field has been correlated with anxiety- and depression-like behaviors in rodents (El Yacoubi et al, 2003). Locomotor activity was measured as the total ambulatory distance in a 5-min session. Two-way ANOVA revealed that the chronic groups showed significantly less locomotor activity than sub-chronic groups, regardless of whether the animals were exposed to stressors or not (main effect stress: $\mathrm{F}(1,44)=0.246, p>0.05$; main effect time: $\mathrm{F}(1,44)=7.986$, $p<0.01$; stress $\times$ time interaction: $\mathrm{F}(1,44)=0, \quad p>0.05$; Supplementary Figure S2a, 2c). On the other hand, the time spent in the center square of the open field is not significantly different among the four groups (main effect stress: $\mathrm{F}(1,44)=3.419, p>0.05$; main effect time: $\mathrm{F}(1,44)=0.884$, $p>0.05$; stress $\times$ time interaction: $\mathrm{F}(1,44)=0.705, p>0.05$; Supplementary Figure S2b, 2c).

FST is a common behavioral test for detecting depressionlike behaviors and for screening antidepressants (Porsolt et al, 1977). Two-way ANOVA demonstrates that mice exposed to CUS show a significant increase in the immobility time of the FST, whereas those exposed to sub-CUS are not significantly different from control (main effect stress: $\mathrm{F}(1,44)=38.549, p<0.001$; main effect time: $\mathrm{F}(1,44)=16.448, \quad p<0.001 ; \quad$ stress $\times$ time interaction: $\mathrm{F}(1,44)=19.575, p<0.001$; control (for sub-CUS) $v s$ subCUS, $p>0.05$; control (for CUS) $v s$ CUS, $p<0.001$; sub-CUS vs CUS, $p<0.001$; Tukey's post hoc test; Figure 2d).

The NSF test is another behavioral paradigm used to assess anxiety and motivation in mice (Santarelli et al, 2003). Exposure of mice to CUS, but not to sub-CUS, significantly increased the latency to feed in the novel environment (main effect stress: $\mathrm{F}(1,44)=9.238, p<0.01$; main effect time: $\mathrm{F}(1,44)=30.837, p<0.001$; stress $\times$ time interaction: $\mathrm{F}(1,44)=17.976, p<0.001$; control (for subCUS) vs sub-CUS, $p>0.05$; control (for CUS) vs CUS, $p<0.001$; sub-CUS $v$ s CUS, $p<0.001$; Tukey's post hoc test; Figure 2e; Supplementary videos S1 and S2). In contrast, neither sub-CUS nor CUS had significant effects on the latency to feed in the home cage, which was measured immediately after the test for feeding in the novel environment (main effect stress: $\mathrm{F}(1,44)=0.872, p>0.05$; main effect time: $\mathrm{F}(1,44)=7.220, p<0.05$; stress $\times$ time interaction: $F(1,44)=0.129, p>0.05$; Figure $2 \mathrm{f})$. Thus, changes in appetite induced by CUS cannot account for the increased latency to feed in the novel environment in NSF test.

In addition to the behavioral profile exhibited, animals exposed to CUS show adrenal hypertrophy and thymus hypotrophy (Muscat and Willner, 1992; Kubera et al, 1995; Willner, 2005; Leonard and Myint, 2009). At 2-7 days after the last behavioral test, mice were killed, blood was collected, and adrenals and thymuses were excised and weighed immediately. Control and stressed mice were timematched and alternated in these experiments. CUS, but not sub-CUS, significantly increased the absolute adrenal weight (main effect stress: $\mathrm{F}(1,28)=9.803, p<0.01$; main effect time: $\mathrm{F}(1,28)=8.953, p<0.01$; stress $\times$ time interaction: $\mathrm{F}(1,28)=15.030, \quad p<0.001$; control $v s$ CUS, $p<0.001$; Tukey's post hoc test; Figure $3 \mathrm{a}$ ) and the relative adrenal weight (ie, adrenal weight normalized to body weight; main effect stress: $\mathrm{F}(1,28)=17.320, p<0.001$; main effect time: $F(1,28)=5.179, p<0.05$; stress $\times$ time interaction: $\mathrm{F}(1,28)=25.510, \quad p<0.001$; control $v s$ CUS, $p<0.001$; Tukey's post hoc test; Figure 3b).

Compared with control, thymus weight was decreased in CUS-exposed mice, but not in sub-CUS mice (main effect stress: $\mathrm{F}(1,28)=8.451, p<0.01$; main effect time: $\mathrm{F}(1,28)=12.491, \quad p=0.001 ; \quad$ stress $\times$ time interaction: $\mathrm{F}(1,28)=5.104, p<0.05$; control $v$ C CUS, $p<0.001$; Tukey's post hoc test; Figure 3c). Stress had a main effect on the relative thymus weight, and this effect was independent of time of exposure (ie, sub-chronic or chronic; main effect stress: $\mathrm{F}(1,28)=4.587, p<0.05$; main effect time: $\mathrm{F}(1,28)=15.872, \quad p<0.001 ; \quad$ stress $\times$ time interaction: $\mathrm{F}(1,28)=2.408, p>0.05$; Figure $3 \mathrm{~d})$. Neither sub-CUS nor CUS had any significant effect on the serum levels of corticosterone (main effect stress: $\mathrm{F}(1,28)=2.749, p>0.05$; main effect time: $\mathrm{F}(1,28)=0.069, p>0.05$; stress $\times$ time interaction: $\mathrm{F}(1,28)=0.405, p>0.05$; Table 1$)$. Thus, the CUS paradigm used in the present study is effective, as it induced a sustained hyperactivity of the hypothalamuspituitary-adrenal axis and suppression of the immune system (Muscat and Willner, 1992; Kubera et al, 1995; Willner, 2005; Leonard and Myint, 2009). However, during the time of testing, the serum levels of corticosterone were a
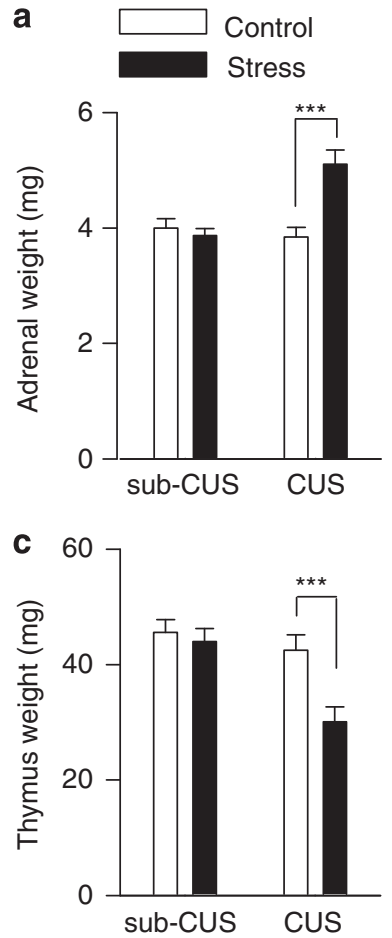

b

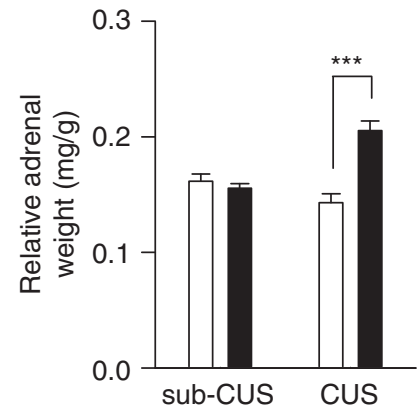

d

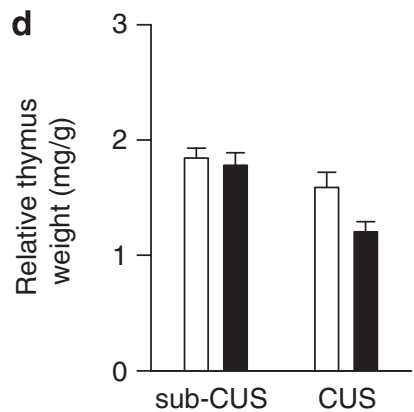

Figure 3 Effects of sub-CUS and CUS on weights of adrenals and thymuses. (a, b) CUS, but not sub-CUS, significantly increased the absolute adrenal weight (**** $p<0.00 \mathrm{I}$ ) (a) and relative adrenal weight $\left(*^{*} *^{*} p<0.00 \mathrm{I}\right.$ ) (b). (c) The absolute thymus weight was decreased in CUS-exposed mice ( $n=8$ for each group; **** $p<0.00$ I). (d) Neither CUS nor sub-CUS had significant effects on the relative thymus weight ( $p>0.05$; $n=8$ for each group). 
unchanged in stress-exposed mice, indicating that CUSexposed mice did not have alterations in the level of basal glucocorticoids 2-7 days after the last stress exposure.

Table I Neither Sub-CUS nor CUS had Significant Effects on the Serum Levels of Corticosterone ( $n=8$ for each group)

Corticosterone $(\mathrm{ng} / \mathrm{ml})$

\begin{tabular}{ll}
\hline Control (for sub-CUS) & $50.12 \pm 6.36$ \\
Sub-CUS & $76.57 \pm 12.10$ \\
Control (for CUS) & $60.48 \pm 13.04$ \\
CUS & $65.73 \pm 14.64$ \\
\hline
\end{tabular}

\section{CUS, but not Sub-CUS, Impairs eCB/CB1 Receptor- Mediated Synaptic Plasticity in the NAc Core}

We examined the effects of sub-CUS and CUS on DSE and LTD in NAc slices prepared from the same groups of mice shown in Figure 2. DSE was induced by a 5-s depolarization step from -80 to $0 \mathrm{mV}$, in the presence of DHPG $(5 \mu \mathrm{M})$. Sub-CUS had no significant effect on the magnitude or decay time constant of DSE ( $\tau$ : control, $10.5 \pm 1.7 \mathrm{~s}, n=7$; sub-CUS, $12.5 \pm 1.9 \mathrm{~s}, n=9 ; p>0.05$; Figure $4 \mathrm{a})$. On the other hand, CUS significantly decreased the magnitude of DSE $(p<0.05)$, although it had no significant effect on the decay time constant of DSE ( $\tau$ : control, $14.9 \pm 2.3 \mathrm{~s}, n=9$; CUS, $10.2 \pm 1.8 \mathrm{~s}, n=9$; $p>0.05$; Figure $4 \mathrm{~b}$ ). Thus, CUS, but not sub-CUS, impairs DSE induction in the NAc.
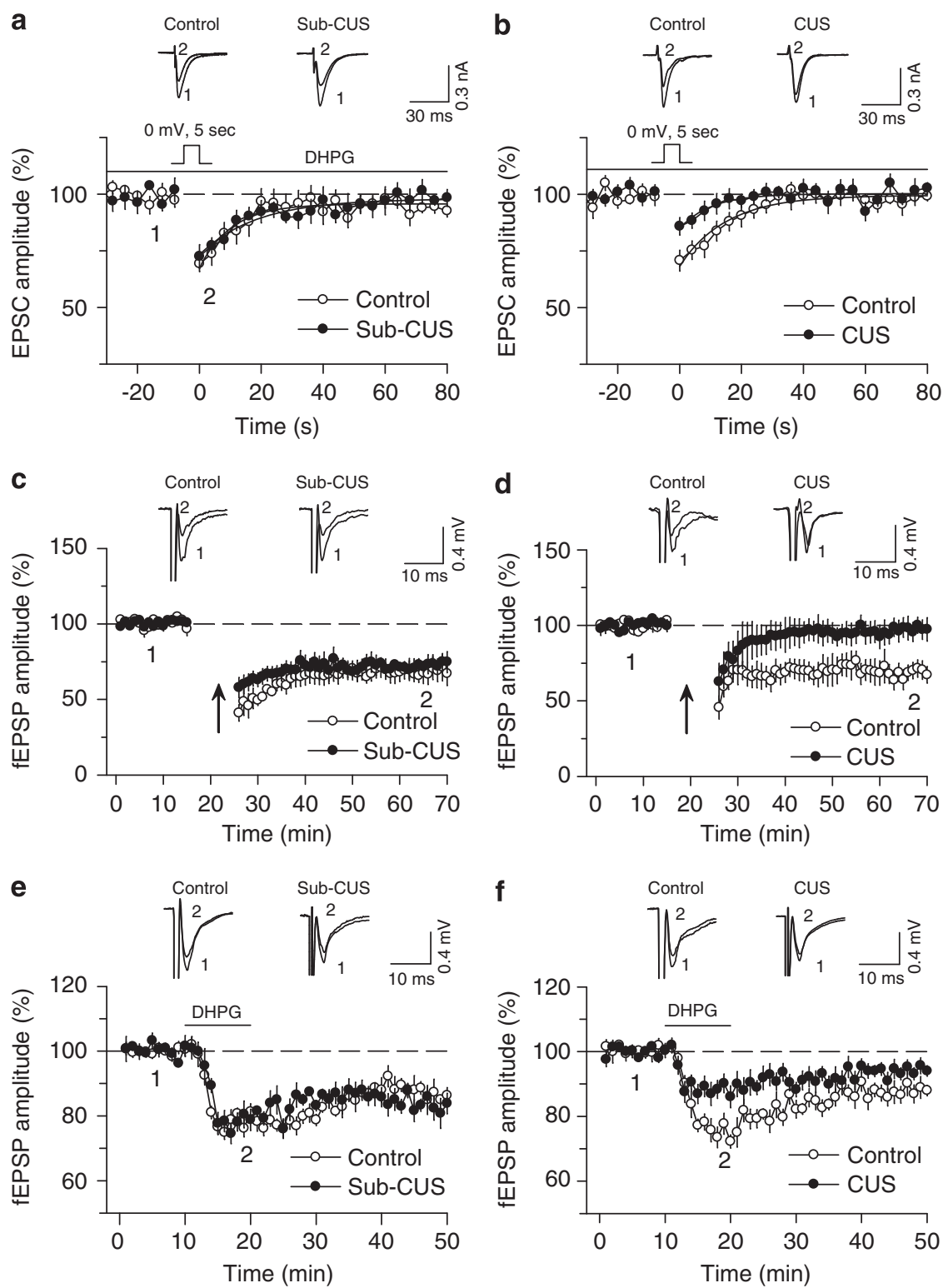

Figure 4 CUS, but not sub-CUS, decreases eCB/CBI receptor-mediated responses in the NAc. (a) DSE was not significantly different between control and sub-CUS groups ( $p>0.05 ; n=7-9$ ). (b) The magnitude of DSE was significantly decreased in the CUS group compared with that of control group $(p<0.05 ; n=9$ for each group). (c) LTD in the NAc was not significantly different between the control group and the sub-CUS group ( $n=8$ for each group). (d) LTD was induced in the NAc in control mice, but not in CUS-exposed mice $(p<0.0 \mid ; n=7-8)$. (e) Group I mGluR agonist DHPG (I00 $\mu$ M) induced similar depression of fEPSPs in slices from sub-CUS-exposed mice and control mice $(p>0.05 ; n=6$ each). (f) DHPG induced significantly less depression in slices from CUS-exposed mice than that from control mice $(p<0.05 ; n=6$ each). 
We examined whether DHPG, at the concentration used in the present study, affected baseline fEPSPs in the NAc. Bath application of $5 \mu \mathrm{M}$ DHPG had no significant effect on fEPSPs in the NAc in the control group ( $p>0.05 v s$ baseline) and in the CUS group ( $p>0.05$ vs baseline or control group; Supplementary Figure S3a). This result is consistent with previous studies showing that group I mGluR or muscarinic receptor agonists, at concentrations that are too low to alter baseline synaptic transmission, facilitate DSI induction (Diana and Marty, 2004; Hashimotodani et al, 2005; Edwards et al, 2006).

eCB-mediated LTD has been implicated in drug addiction (Gerdeman et al, 2003; Mato et al, 2004), but its role in stress and depression, to our knowledge, has not been explored. We examined the effect of sub-CUS and CUS on eCB-mediated LTD in the NAc. After baseline recordings of fEPSPs at $0.1 \mathrm{~Hz}$, repetitive afferent stimulation $(10 \mathrm{~Hz}$ for 10 min) was applied to induce LTD. LTD in the NAc slices was not significantly different between control and sub-CUS groups ( $p>0.05$; Figure $4 \mathrm{c})$. However, CUS exposure impaired LTD induction in the NAc $(p<0.01$; Figure $4 \mathrm{~d})$.

In the absence of depolarization, a higher concentration $(50 \mu \mathrm{M})$ of DHPG has been shown previously to depress fEPSPs in the NAc core and this depression was blocked by AM 251 (Robbe et al, 2002). Thus, DHPG-induced depression of fEPSPs provides another measure of the strength of endogenous cannabinoid-mediated signaling. Consistent with the previous study (Robbe et al, 2002), we found that bath application of $(100 \mu \mathrm{M})$ DHPG depressed fEPSPs in the NAc core in control mice (Figure 4e), and the effect of DHPG in control mice was blocked by AM 251
(1.5 $\pm 3.1 \%$ of baseline, $n=5)$. We also found that CUS, but not sub-CUS, significantly attenuated DHPG-induced depression of fEPSPs in the NAc core (main effect stress: $\mathrm{F}(1,20)=5.931, p<0.001$; main effect time: $\mathrm{F}(1,20)=4.560$, $p<0.05$; stress $\times$ time interaction: $\mathrm{F}(1,20)=14.531, p<0.01$; control vs sub-CUS, $p>0.05$; control vs CUS, $p<0.001$; Tukey's post hoc test; Figure $4 \mathrm{e}$ and $\mathrm{f}$ ).

CUS-induced impairment of DSE and LTD could be attributed to either a decrease in the $\mathrm{eCB}$ mobilization or a decrease in the CB1 receptor function. To begin discriminating these possibilities, we examined the effect of bath application of the CB1 receptor agonist WIN 55212-2 on fEPSPs in the NAc in slices prepared from the same groups of mice shown in Figure 2. WIN $55212-2(2 \mu \mathrm{M})$ induced similar depression of fEPSPs in slices from sub-CUSexposed mice and control mice ( $p>0.05$; Figure 5a). In contrast, WIN $55212-2$ induced significantly less depression in slices from CUS-exposed mice than in control mice $(p<0.05$; Figure $5 \mathrm{~b})$. The depression of fEPSPs by WIN $55212-2$ in control and stressed mice were reversed by subsequent addition of the CB1 receptor antagonist AM 251 $(4 \mu \mathrm{M}$, Figure 5a and b). CB1 ligands are highly lipophilic compounds that are not readily washed out from the slice, and AM 251 was therefore applied to block the effect of WIN $55212-2$. Bath application of AM $251(4 \mu \mathrm{M})$ alone had no significant effect on baseline fEPSPs in control and CUS groups ( $p>0.05$; Supplementary Figure S3b).

Concentration-response curves for WIN 55212-2-induced depression of fEPSPs were obtained in the NAc in slices prepared from control and stress-exposed mice that were not exposed to the behavioral tests, but were otherwise
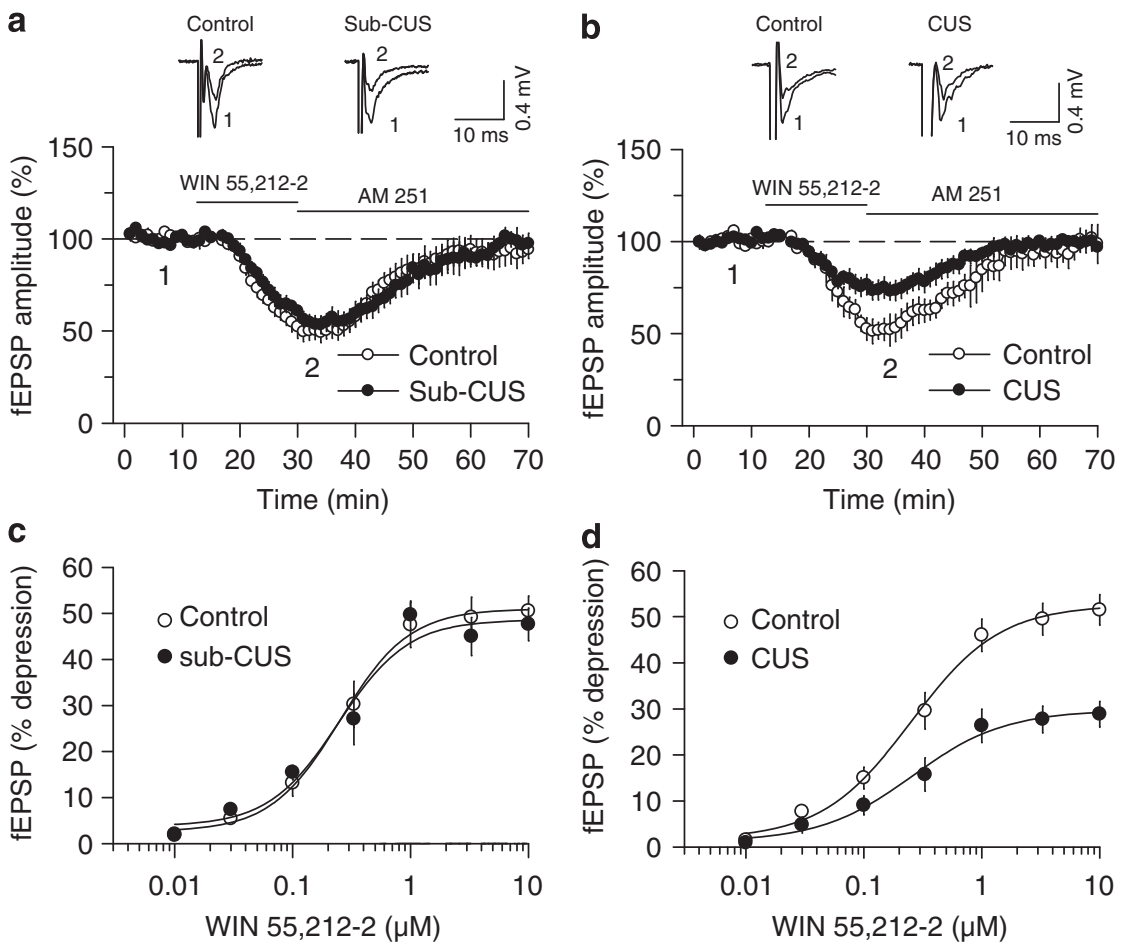

Figure 5 Effects of sub-CUS and CUS on WIN 552 I2-2-induced depression of fEPSPs in the NAc. (a) Sub-CUS had no significant effect on WIN 552 I 2 $2(2 \mu \mathrm{M})$-induced depression of fEPSPs ( $p>0.05 ; n=6-7)$, and the effect of WIN $55212-2$ was reversed by subsequent addition of the CBI antagonist AM 25 I ( $4 \mu \mathrm{M})$. (b) CUS significantly attenuated the effects of WIN $55212-2$ on fEPSPs $(p<0.05 ; n=6-7)$. (c, d) Concentration-response curves for WIN 55 2 12 -2-induced depression of fEPSPs in NAc slices from control, sub-CUS, control, and CUS groups. CUS, but not sub-CUS, decreased the maximal effect of WIN 55 212-2. Neither sub-CUS nor CUS significantly affected the EC 50 or Hill slope of the dose-response curves (see Table 2 for detailed statistics). 
treated identically to the mice used in the above studies. We found that exposure to CUS, but not sub-CUS, decreased the maximal effect $\left(E_{\max }\right)$ of WIN 55 212-2-induced depression of fEPSPs in the NAc core (main effect stress: $F(1,16)=$ 19.429, $p<0.001$; main effect time: $\mathrm{F}(1,16)=$ 8.271, $p<0.05$; stress $\times$ time interaction: $\mathrm{F}(1,16)=11.759$, $p<0.01$; control vs sub-CUS, $p>0.05$; control vs CUS, $p<0.001$; sub-CUS vs CUS, $p<0.001$; Tukey's post hoc test; Figure $5 c$ and $d$ and Table 2). Neither sub-CUS nor CUS had any significant effect on $\mathrm{EC}_{50}$ (main effect stress: $\mathrm{F}(1,16)=0.037, p>0.05$; main effect time: $\mathrm{F}(1,16)=0.250$, $p>0.05$; stress $\times$ time interaction: $\mathrm{F}(1,16)=0, p>0.05$; Table 2) or Hill slope (main effect stress: $F(1,16)=0.002$, $p>0.05$; main effect time: $\mathrm{F}(1,16)=3.222, \quad p>0.05$; stress $\times$ time interaction: $\mathrm{F}(1,16)=0.325, p>0.05$; Table 2 ). Thus, CUS altered the maximal response of WIN $55212-2-$ induced depression of fEPSPs, but did not affect the affinity of WIN 55 212-2 binding to the CB1 receptor. Note that the maximal depression of fEPSPs $(\sim 50 \%)$ induced by WIN $55212-2$ in Figure 5c and d (in slices from mice not exposed to behavioral tests) was comparable to the depression induced by $2 \mu \mathrm{M}$ WIN $55212-2$ in Figure $5 \mathrm{a}$ and b (in slices from mice exposed to behavioral tests).

We examined the effect of sub-CUS and CUS exposure on the tissue contents of the eCBs AEA and 2-AG in the striatum. Neither sub-CUS nor CUS exposure had significant effects on the tissue content of 2-AG (main effect stress: $\mathrm{F}(1,20)=1.956, p>0.05$; main effect time: $\mathrm{F}(1,20)=0.936$, $p>0.05$; stress $\times$ time interaction: $\mathrm{F}(1,20)=0.207, p>0.05)$ or AEA (main effect stress: $\mathrm{F}(1,20)=0.023, p>0.05$; main effect time: $\mathrm{F}(1,20)=0.545, p>0.05$; stress $\times$ time interaction: $\mathrm{F}(1,20)=0.0846, p>0.05$; Table 3$)$.

Table 2 Fitting Concentration-Response Data Yielded EC $\mathrm{E}_{50}, E_{\max }$ and Hill Slope of WIN 55 212-2-Induced Depression of fEPSPs in NAc in Slices Obtained from Control, Sub-CUS, Control, and CUS Groups ( $n=6$ for each group)

\begin{tabular}{llll}
\hline & $\boldsymbol{E}_{\max }(\%)$ & $\mathbf{E C}_{\mathbf{5 0}}(\boldsymbol{\mu} \mathbf{M})$ & Slope \\
\hline Control (for sub-CUS) & $51.52 \pm 3.50$ & $0.27 \pm 0.04$ & $1.66 \pm 0.22$ \\
Sub-CUS & $48.57 \pm 3.40$ & $0.26 \pm 0.08$ & $1.79 \pm 0.39$ \\
Control (for CUS) & $53.19 \pm 2.90$ & $0.30 \pm 0.06$ & $1.36 \pm 0.16$ \\
CUS & $29.57 \pm 2.02 * * * *$ & $0.29 \pm 0.06$ & $1.21 \pm 0.10$ \\
\hline
\end{tabular}

***** $p<0.00$ I CUS vs control or sub-CUS.

Table 3 Neither Sub-CUS nor CUS Had Significant Effects on Tissue Content of 2-AG and AEA in the Striatum ( $p>0.05$; $n=5-7$ for each group)

2-AG (nmol/g tissue) AEA (pmol/g tissue)

\begin{tabular}{lll}
\hline Control (for sub-CUS) & $13.16 \pm 0.91$ & $4.92 \pm 0.87$ \\
Sub-CUS & $16.54 \pm 2.87$ & $5.03 \pm 0.70$ \\
Control (for CUS) & $12.22 \pm 0.70$ & $5.80 \pm 1.26$ \\
CUS & $13.95 \pm 1.83$ & $5.42 \pm 0.54$ \\
\hline
\end{tabular}

\section{Effects of Antidepressant Fluoxetine on CUS-Induced Abnormalities of Behavior and eCB Signaling}

We examined the effect of in vivo administration of the antidepressant fluoxetine on CUS-induced changes in behavior and $\mathrm{eCB} / \mathrm{CB} 1$ receptor-mediated responses in the NAc. Mice were exposed to CUS for a total of 8 weeks. At the beginning of the fifth week, CUS-exposed mice and time-matched control mice were given daily i.p. injections of fluoxetine $(10 \mathrm{mg} / \mathrm{kg})$ or vehicle $(0.9 \% \mathrm{NaCl})$ for 4 weeks. The time course for stress exposure and drug treatment is shown in Figure 6a. The behavioral tests were started $72 \mathrm{~h}$ after the last treatment to exclude acute drug effects on the behavior (Lopez-Rubalcava and Lucki, 2000).

A two-way ANOVA showed that CUS significantly decreased the sucrose intake, and fluoxetine treatment restored CUS-induced reduction of the sucrose intake (main effect CUS: $\mathrm{F}(1,36)=20.797, p<0.001$; main effect treatment: $\mathrm{F}(1,36)=1.554, p>0.05$; CUS $\times$ treatment interaction: $\mathrm{F}(1,36)=8.738, p<0.01$; control-vehicle $v s$ CUSvehicle, $p<0.001$; CUS-vehicle vs CUS-fluoxetine, $p<0.01$; Tukey's post hoc test; Figure 6b).

In the FST, CUS exposure significantly increased the immobility time; chronic fluoxetine treatment significantly decreased the immobility time regardless of stress exposure (main effect CUS: $\mathrm{F}(1,36)=19.028, p<0.001$; main effect treatment: $\mathrm{F}(1,36)=15.380, \quad p<0.001 ; \quad$ CUS $\times$ treatment interaction: $\mathrm{F}(1,36)=0.674, p>0.05$; Figure $6 \mathrm{c})$. CUS induced a significant increase in the latency to feed in the novel environment in NSF test, which was reversed by fluoxetine treatment (main effect CUS: $\mathrm{F}(1,36)=7.519$, $p<0.01$; main effect treatment: $\mathrm{F}(1,36)=5.075, p<0.05$; CUS $\times$ treatment interaction: $\mathrm{F}(1,36)=4.247, \quad p<0.05$; control-vehicle vs CUS-vehicle, $p<0.01$; CUS-vehicle $v s$ CUS-fluoxetine, $p<0.01$; Tukey's post hoc test; Figure $6 \mathrm{~d}$ ). However, neither CUS nor fluoxetine treatment affected the latency to feed in the home cage (main effect CUS: $\mathrm{F}(1,36)=2.418, p>0.05$; main effect treatment: $\mathrm{F}(1,36)=$ 1.877, $p>0.05$; CUS $\times$ treatment interaction: $\mathrm{F}(1,36)=0.770$, $p>0.05$; Figure 6e).

We compared DSE-, LTD-, and WIN 55212-2-induced depression of fEPSPs in slices prepared from fluoxetineand vehicle-treated control and stressed mice. The recordings of these three eCB/CB1 receptor-mediated responses were similar to those described above. Chronic fluoxetine administration had no significant effect on the magnitude of DSE- ( $p>0.05$; Figure 6f), LTD- $(p>0.05$; Figure 6g), and WIN 55212-2-induced depression of fEPSPs $(p>0.05$; Figure $6 \mathrm{~h})$ in control mice. However, chronic fluoxetine administration prevented CUS-induced decrease in the magnitude of DSE- $(p<0.01$; Figure $6 f)$, LTD- $(p<0.01$; Figure 6g), and WIN 55 212-2-induced depression of fEPSPs $(p<0.01$; Figure 6h).

\section{DISCUSSION}

CUS satisfies the criteria of predictive validity (pharmacological profile), face validity (symptom profile), and construct validity (theoretical rationale) as a behavioral model for depression (Willner, 2005). Although it met with some criticisms initially, the CUS model has been validated by many independent studies (see the references cited by 
a
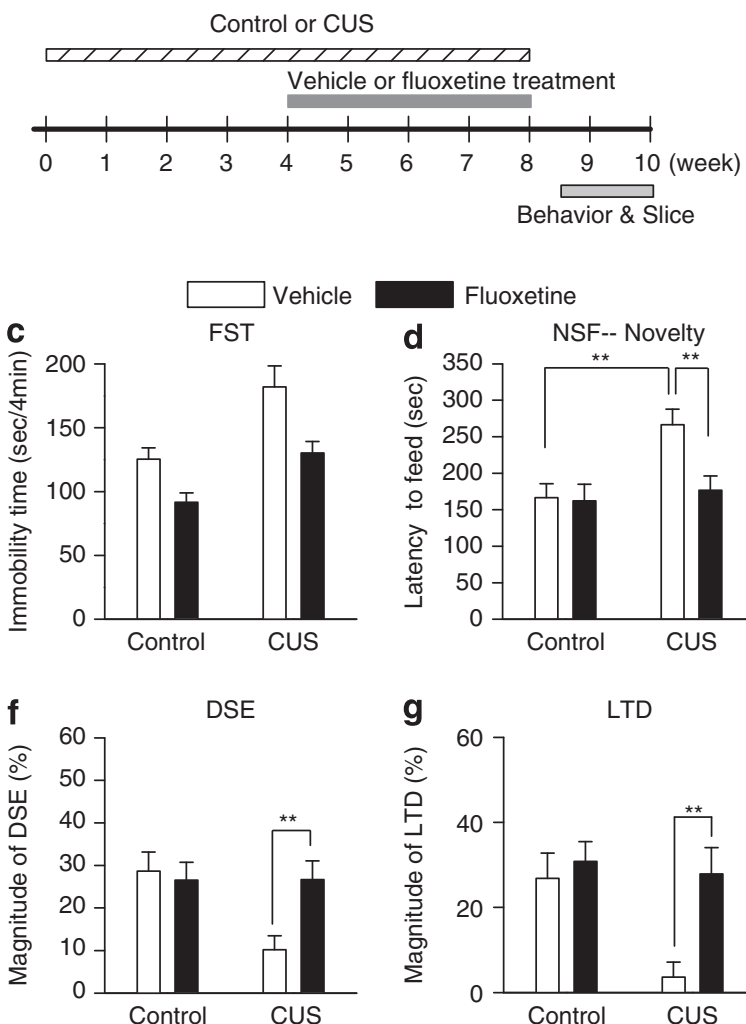

b
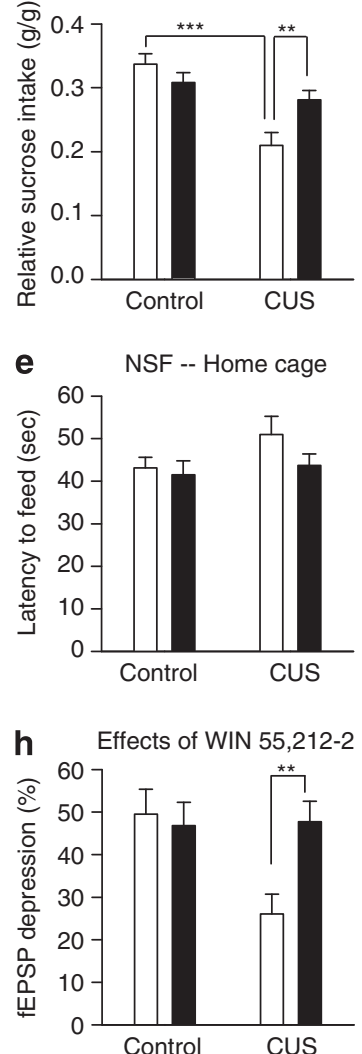

Figure 6 Chronic fluoxetine treatment produces antidepressant behavioral effects and reverses CUS-induced deficiency in eCB/CBI-mediated responses in the NAc. (a) Time course of the CUS exposure, antidepressant treatment, behavioral tests, and slice electrophysiology. (b) CUS significantly decreased relative sucrose intake $(* * * *<0.00 \mathrm{I})$, whereas fluoxetine treatment significantly increased relative sucrose intake in CUS group $(* * p<0.0 \mathrm{I}$ ), but not in control group ( $n=10$ for each group). (c) There were main effects of CUS and fluoxetine on the immobility time in the FST; however, the lack of significant interaction between CUS and fluoxetine precludes post hoc comparison of individual groups. (d) CUS induced a significant increase in the latency to feed in the novel environment in NSF test $(* * p<0.0 \mathrm{I})$, which was reversed by fluoxetine treatment $(* * p<0.0 \mathrm{I})$. (e) Neither CUS nor fluoxetine treatment affected the latency to feed in the home cage in NSF test. $(f-h)$ CUS exposure significantly decreased the magnitude of DSE ( $f$ ), LTD (g), and WIN 552 I22-induced depression of fEPSPs (h), and chronic fluoxetine treatment reversed CUS-induced decrease in these eCB/CBI receptor-mediated responses (*** $p<0.01 ; n=6-9)$.

Willner, 1997, 2005). Notably, chronic, but not acute, antidepressant treatment reverses depression-like behaviors in CUS-exposed animals, consistent with the time course for the therapeutic actions of antidepressants in humans (Willner, 2005). CUS is considered 'one of the best animal models that capture core symptoms of depression' (Duman, 2007). The present study shows that CUS, but not sub-CUS, induces depression-like behaviors and causes deficiency in eCB/CB1 receptor-mediated responses in the NAc, both of which can be reversed by chronic administration of the antidepressant fluoxetine. These results indicate that downregulation of eCB signaling occurs in the NAc in an animal model of depression.

\section{Neuroplasticity in the NAc and Depression}

There is an emerging concept that neuroplasticity has an important role in the pathophysiology of stress and depression and in the action of antidepressants (Pittenger and Duman, 2008). The challenge is to identify such plastic changes in specific brain regions that are linked to depressive behaviors. In recent years, there has been an increasing appreciation of the role of the brain's reward circuitry in depression and antidepressant treatment (Nestler and Carlezon, 2006). The NAc is an important component of the reward circuitry, and dysfunction of the NAc could account for anhedonia, lack of motivation, and other symptoms of depression (Nestler and Carlezon, 2006). Consistent with this idea, deep-brain stimulation of the NAc produces an acute relief of depressive symptoms in depressed patients (Schlaepfer et al, 2008). Animal studies have shown that long-lasting changes in gene regulation and protein expression occur in the NAc in several animal models of depression and antidepressant treatment (Shirayama et al, 2004; Chartoff et al, 2009; Wilkinson et al, 2009).

The present study has identified long-term plasticity of eCB signaling in the NAc as a form of neuroplasticity that could potentially link stress to depressive behaviors. The deficiency in eCB/CB1-mediated responses in the NAc is accompanied by behavioral changes. Sub-CUS, which did not have significant effects on behavior, did not affect eCB/CB1-mediated responses in the NAc, whereas CUS, which induced depression-like behavior, caused persistent downregulation of eCB/CB1-mediated responses in the NAc. Furthermore, in vivo administration of antidepressant 
fluoxetine prevented CUS-induced deficiency in eCB/CB1mediated responses in the NAc and produced antidepressant effects on behavior. Given the critical role of the NAc in reward sensing and processing (Nestler and Carlezon, 2006), CUS-induced deficiency in $\mathrm{eCB}$ signaling in the NAc could contribute to certain depression-like behaviors, such as anhedonia and lack of motivation. However, it is unlikely that such deficiency accounts for all CUS-induced depression-like behaviors.

In sharp contrast to the CUS-fluoxetine group, the timematched CUS-vehicle group still showed deficiency in eCB/ CB1 receptor-mediated responses in the NAc and depression-like behaviors, suggesting that the effects of fluoxetine are not the consequence of the habituation of mice to the CUS (ie, the prolongation of CUS from 5-6 to 8 weeks), but the consequence of antidepressant action. The mechanism by which fluoxetine prevents CUS-induced deficiency in eCB/CB1-mediated responses in the NAc is not clear. Antidepressant manipulations, such as electroconvulsive shock and tricyclic antidepressants, increase $\mathrm{CB} 1$ receptor activity in the hippocampus, amygdala, and hypothalamus (Hill et al, 2006, 2007). It is possible that fluoxetine treatment can overcome the CUS-induced decrease in CB1 receptor activity in the NAc.

\section{The eCB System in Depression}

Accumulating evidence indicates that the eCB system is critically involved in mood disorders such as depression and anxiety. The eCB system is altered in patients with depression and in animal models of depression. Serum concentrations of 2-AG are reduced in women with major depression compared with a matched control group (Hill et al, 2008b). We have found previously that rats exposed to CUS showed a decrease in the tissue content of AEA in the $\mathrm{NAc}$ and other brain regions, whereas 2-AG content in the $\mathrm{NAc}$ and most other brain regions remained unchanged (Hill et al, 2008a). In contrast, another study found that CUS did not change AEA and 2-AG contents in the striatum and in most other brains in CUS-exposed rats (Bortolato et al, 2007). The methodological differences, such as the time for tissue collection, might be responsible for the discrepancies (Hill et al, 2008a). The present study has shown that neither sub-CUS nor CUS significantly affected 2-AG and AEA contents in the mouse striatum. However, in these studies, 2-AG and AEA contents were measured in tissue chunks, and the lack of temporal and spatial resolution does not permit a firm conclusion of whether $\mathrm{eCB} / \mathrm{CB} 1$ receptor-mediated function is altered in animal models of depression.

Using electrophysiological recordings from NAc slices, we show here that CUS, but not sub-CUS, impairs endogenous cannabinoid-mediated responses, including DSE, LTD, and DHPG-induced depression of fEPSPs, in the NAc. The deficiency in eCB-mediated responses could be because of a decrease in $\mathrm{CB} 1$ receptor signaling or a decrease in eCB production. CUS, but not sub-CUS, decreased the maximal effect, but did not affect the EC $_{50}$ of WIN 55212-2-induced depression of fEPSPs. As WIN 55212-2 is an exogenous $\mathrm{CB} 1$ agonist, the above results suggest that CUS-induced decrease in CB1 receptor expression and/or signaling is responsible for the deficiency in DSE, LTD, and DHPG- induced depression of fEPSPs. This conclusion is supported by a previous study showing that CUS reduced the CB1 receptor-binding site density in the NAc (Hill et al, 2008a). However, we cannot rule out the possibility that eCB production is decreased by CUS. It has been shown that social defeat stress (exposure to an aggressor) decreases the depression of spontaneous IPSCs induced by the CB1 agonist HU210 and the group I mGluR agonist DHPG in the dorsal striatum (Rossi et al, 2008). Taken together, these studies indicate that the eCB-mediated transmission is downregulated in the ventral (ie, NAc) and dorsal striatum in animal models of depression.

It has been shown that inhibition of $\mathrm{eCB} / \mathrm{CB} 1$ receptor activity has a negative impact on mood and emotion. CB1 receptor knockout mice show depression- and anxiety-like behaviors, including increased susceptibility to developing anhedonia in response to CUS and perseverance of emotionally aversive memories (Martin et al, 2002; Hill and Gorzalka, 2005). CB1 receptor antagonists SR141716 (rimonabant) and AM251 produce anxiogenic-like effects in rodents (Navarro et al, 1997; Haller et al, 2004; Rodgers et al, 2005), and rimonabant increases the incidence of anxiety and depression in clinical trials for the treatment of obesity (Samat et al, 2008). Although these studies have shown that pharmacological blockade and genetic deletion of $\mathrm{CB} 1$ receptors produce depression-like phenotypes, we show here that 'natural' pathophysiological stimuli (ie, CUS) caused a deficiency in eCB signaling and depressionlike behaviors. These results strongly suggest that CUSinduced deficiency in eCB signaling contributes to certain symptoms of depression.

A recent study has shown that repeated homotypic stress (restraint) elevates 2-AG levels and enhances DSI- and WIN 55212-2-induced depression of inhibitory synaptic transmission in the amygdala (Patel et al, 2009). Repeated homotypic stress may induce habituation of the animals to stress and produce different effects on eCB/CB1-mediated responses. Alternatively, stress may enhance or dampen the eCB/CB1 receptor-mediated responses, depending on the brain regions involved.

In conclusion, the present study shows that CUS causes persistent deficiency in eCB/CB1 receptor-mediated responses in the NAc, which can be reversed by chronic administration of the antidepressant fluoxetine. The identification of CUS-induced abnormalities of eCB signaling in the NAc contributes to our understanding of the mechanism of depression and designing strategies for therapeutic intervention of depression.

\section{ACKNOWLEDGEMENTS}

This work was supported by National Institutes of Health Grants DA022439 (CJH) and DA024741 (QSL), by NARSAD: the Mental Health Research Association (QSL), and by Advancing a Healthier Wisconsin endowment at the Medical College of Wisconsin (CJH and QSL).

\section{DISCLOSURE}

The authors declare no conflict of interest. 


\section{REFERENCES}

Alger BE (2005). Endocannabinoid identification in the brain: studies of breakdown lead to breakthrough, and there may be NO hope. Sci STKE 2005: pe51.

Berrendero F, Maldonado R (2002). Involvement of the opioid system in the anxiolytic-like effects induced by Delta(9)tetrahydrocannabinol. Psychopharmacology (Berl) 163: 111-117.

Bortolato M, Mangieri RA, Fu J, Kim JH, Arguello O, Duranti A et al (2007). Antidepressant-like activity of the fatty acid amide hydrolase inhibitor URB597 in a rat model of chronic mild stress. Biol Psychiatry 62: 1103-1110.

Chartoff EH, Papadopoulou M, MacDonald ML, Parsegian A, Potter D, Konradi C et al (2009). Desipramine reduces stressactivated dynorphin expression and CREB phosphorylation in NAc tissue. Mol Pharmacol 75: 704-712.

Dehorter N, Guigoni C, Lopez C, Hirsch J, Eusebio A, Ben-Ari Y et al (2009). Dopamine-deprived striatal GABAergic interneurons burst and generate repetitive gigantic IPSCs in medium spiny neurons. J Neurosci 29: 7776-7787.

Diana MA, Marty A (2004). Endocannabinoid-mediated short-term synaptic plasticity: depolarization-induced suppression of inhibition (DSI) and depolarization-induced suppression of excitation (DSE). Br J Pharmacol 142: 9-19.

Duman RS (2007). A silver bullet for the treatment of depression? Neuron 55: 679-681.

Edwards DA, Kim J, Alger BE (2006). Multiple mechanisms of endocannabinoid response initiation in hippocampus. $J$ Neurophysiol 95: 67-75.

El Yacoubi M, Bouali S, Popa D, Naudon L, Leroux-Nicollet I, Hamon $M$ et al (2003). Behavioral, neurochemical, and electrophysiological characterization of a genetic mouse model of depression. Proc Natl Acad Sci USA 100: 6227-6232.

Gerdeman GL, Partridge JG, Lupica CR, Lovinger DM (2003). It could be habit forming: drugs of abuse and striatal synaptic plasticity. Trends Neurosci 26: 184-192.

Gerdeman GL, Ronesi J, Lovinger DM (2002). Postsynaptic endocannabinoid release is critical to long-term depression in the striatum. Nat Neurosci 5: 446-451.

Gobbi G, Bambico FR, Mangieri R, Bortolato M, Campolongo P, Solinas $\mathrm{M}$ et al (2005). Antidepressant-like activity and modulation of brain monoaminergic transmission by blockade of anandamide hydrolysis. Proc Natl Acad Sci USA 102: 1862018625.

Gorzalka BB, Hill MN, Hillard CJ (2008). Regulation of endocannabinoid signaling by stress: implications for stress-related affective disorders. Neurosci Biobehav Rev 32: 1152-1160.

Haller J, Varga B, Ledent C, Freund TF (2004). CB1 cannabinoid receptors mediate anxiolytic effects: convergent genetic and pharmacological evidence with CB1-specific agents. Behav Pharmacol 15: 299-304.

Hashimotodani Y, Ohno-Shosaku T, Tsubokawa H, Ogata H, Emoto K, Maejima T et al (2005). Phospholipase Cbeta serves as a coincidence detector through its $\mathrm{Ca} 2+$ dependency for triggering retrograde endocannabinoid signal. Neuron 45: 257-268.

Heifets BD, Castillo PE (2009). Endocannabinoid signaling and long-term synaptic plasticity. Annu Rev Physiol 71: 283-306.

Herkenham M, Lynn AB, Johnson MR, Melvin LS, de Costa BR, Rice KC (1991). Characterization and localization of cannabinoid receptors in rat brain: a quantitative in vitro autoradiographic study. J Neurosci 11: 563-583.

Hill MN, Barr AM, Ho WS, Carrier EJ, Gorzalka BB, Hillard CJ (2007). Electroconvulsive shock treatment differentially modulates cortical and subcortical endocannabinoid activity. J Neurochem 103: 47-56.

Hill MN, Carrier EJ, McLaughlin RJ, Morrish AC, Meier SE, Hillard CJ et al (2008a). Regional alterations in the endocannabinoid system in an animal model of depression: effects of concurrent antidepressant treatment. J Neurochem 106: 2322-2336.

Hill MN, Gorzalka BB (2005). Is there a role for the endocannabinoid system in the etiology and treatment of melancholic depression? Behav Pharmacol 16: 333-352.

Hill MN, Hillard CJ, Bambico FR, Patel S, Gorzalka BB, Gobbi G (2009). The therapeutic potential of the endocannabinoid system for the development of a novel class of antidepressants. Trends Pharmacol Sci 30: 484-493.

Hill MN, Ho WS, Sinopoli KJ, Viau V, Hillard CJ, Gorzalka BB (2006). Involvement of the endocannabinoid system in the ability of long-term tricyclic antidepressant treatment to suppress stress-induced activation of the hypothalamic-pituitary-adrenal axis. Neuropsychopharmacology 31: 2591-2599.

Hill MN, Miller GE, Ho WS, Gorzalka BB, Hillard CJ (2008b). Serum endocannabinoid content is altered in females with depressive disorders: a preliminary report. Pharmacopsychiatry 41: 48-53.

Hill MN, Patel S, Carrier EJ, Rademacher DJ, Ormerod BK, Hillard CJ et al (2005). Downregulation of endocannabinoid signaling in the hippocampus following chronic unpredictable stress. Neuropsychopharmacology 30: 508-515.

Jiang W, Zhang Y, Xiao L, Van Cleemput J, Ji SP, Bai G et al (2005). Cannabinoids promote embryonic and adult hippocampus neurogenesis and produce anxiolytic- and antidepressant-like effects. J Clin Invest 115: 3104-3116.

Kano M, Ohno-Shosaku T, Hashimotodani Y, Uchigashima M, Watanabe M (2009). Endocannabinoid-mediated control of synaptic transmission. Physiol Rev 89: 309-380.

Koo JW, Duman RS (2008). IL-1beta is an essential mediator of the antineurogenic and anhedonic effects of stress. Proc Natl Acad Sci USA 105: 751-756.

Kreitzer AC, Malenka RC (2005). Dopamine modulation of statedependent endocannabinoid release and long-term depression in the striatum. J Neurosci 25: 10537-10545.

Kreitzer AC, Regehr WG (2001). Retrograde inhibition of presynaptic calcium influx by endogenous cannabinoids at excitatory synapses onto Purkinje cells. Neuron 29: 717-727.

Kubera M, Basta-Kaim A, Papp M (1995). The effect of chronic treatment with imipramine on the immunoreactivity of animals subjected to a chronic mild stress model of depression. Immunopharmacology 30: 225-230.

Leonard BE, Myint A (2009). The psychoneuroimmunology of depression. Hum Psychopharmacol 24: 165-175.

Lopez-Rubalcava C, Lucki I (2000). Strain differences in the behavioral effects of antidepressant drugs in the rat forced swimming test. Neuropsychopharmacology 22: 191-199.

Lutz B (2009). Endocannabinoid signals in the control of emotion. Curr Opin Pharmacol 9: 46-52.

Maejima T, Hashimoto K, Yoshida T, Aiba A, Kano M (2001). Presynaptic inhibition caused by retrograde signal from metabotropic glutamate to cannabinoid receptors. Neuron 31: 463-475.

Mangieri RA, Piomelli D (2007). Enhancement of endocannabinoid signaling and the pharmacotherapy of depression. Pharmacol Res 56: 360-366.

Martin M, Ledent C, Parmentier M, Maldonado R, Valverde O (2002). Involvement of CB1 cannabinoid receptors in emotional behaviour. Psychopharmacology (Berl) 159: 379-387.

Mato S, Chevaleyre V, Robbe D, Pazos A, Castillo PE, Manzoni OJ (2004). A single in-vivo exposure to delta 9THC blocks endocannabinoid-mediated synaptic plasticity. Nat Neurosci 7: 585-586.

Meredith GE (1999). The synaptic framework for chemical signaling in nucleus accumbens. Ann N Y Acad Sci 877: 140-156.

Muscat R, Willner P (1992). Suppression of sucrose drinking by chronic mild unpredictable stress: a methodological analysis. Neurosci Biobehav Rev 16: 507-517. 
Narushima M, Hashimoto K, Kano M (2006). Endocannabinoidmediated short-term suppression of excitatory synaptic transmission to medium spiny neurons in the striatum. Neurosci Res 54: 159-164.

Navarro M, Hernandez E, Munoz RM, del Arco I, Villanua MA, Carrera MR et al (1997). Acute administration of the CB1 cannabinoid receptor antagonist SR 141716A induces anxietylike responses in the rat. Neuroreport 8: 491-496.

Nestler EJ, Carlezon Jr WA (2006). The mesolimbic dopamine reward circuit in depression. Biol Psychiatry 59: 1151-1159.

Ohno-Shosaku T, Maejima T, Kano M (2001). Endogenous cannabinoids mediate retrograde signals from depolarized postsynaptic neurons to presynaptic terminals. Neuron 29: 729-738.

Pan B, Hillard CJ, Liu QS (2008a). Endocannabinoid signaling mediates cocaine-induced inhibitory synaptic plasticity in midbrain dopamine neurons. J Neurosci 28: 1385-1397.

Pan B, Hillard CJ, Liu QS (2008b). D2 dopamine receptor activation facilitates endocannabinoid-mediated long-term synaptic depression of GABAergic synaptic transmission in midbrain dopamine neurons via cAMP-protein kinase A signaling. J Neurosci 28: 14018-14030.

Pan B, Wang W, Long JZ, Sun D, Hillard CJ, Cravatt BF et al (2009). Blockade of 2-arachidonoylglycerol hydrolysis by selective monoacylglycerol lipase inhibitor 4-nitrophenyl 4-(dibenzo[d][1,3] dioxol-5-yl(hydroxy)methyl)piperidine-1-carboxylate (JZL184) enhances retrograde endocannabinoid signaling. J Pharmacol Exp Ther 331: 591-597.

Patel S, Hillard CJ (2006). Pharmacological evaluation of cannabinoid receptor ligands in a mouse model of anxiety: further evidence for an anxiolytic role for endogenous cannabinoid signaling. J Pharmacol Exp Ther 318: 304-311.

Patel S, Kingsley PJ, Mackie K, Marnett LJ, Winder DG (2009). Repeated homotypic stress elevates 2-arachidonoylglycerol levels and enhances short-term endocannabinoid signaling at inhibitory synapses in basolateral amygdala. Neuropsychopharmacology 34: 2699-2709.

Patel S, Rademacher DJ, Hillard CJ (2003). Differential regulation of the endocannabinoids anandamide and 2-arachidonylglycerol within the limbic forebrain by dopamine receptor activity. J Pharmacol Exp Ther 306: 880-888.

Patel S, Roelke CT, Rademacher DJ, Cullinan WE, Hillard CJ (2004). Endocannabinoid signaling negatively modulates stressinduced activation of the hypothalamic-pituitary-adrenal axis. Endocrinology 145: 5431-5438.

Paxinos G, Watson C (1986). The Rat Brain in Stereotaxic Coordinates Compact 3rd edn. Academic Press: Sydney, Orlando.

Pickel VM, Chan J, Kash TL, Rodriguez JJ, MacKie K (2004). Compartment-specific localization of cannabinoid 1 (CB1) and mu-opioid receptors in rat nucleus accumbens. Neuroscience 127: $101-112$.

Pitler TA, Alger BE (1992). Postsynaptic spike firing reduces synaptic GABAA responses in hippocampal pyramidal cells. J Neurosci 12: 4122-4132.

Pittenger C, Duman RS (2008). Stress, depression, and neuroplasticity: a convergence of mechanisms. Neuropsychopharmacology 33: 88-109.
Porsolt RD, Le Pichon M, Jalfre M (1977). Depression: a new animal model sensitive to antidepressant treatments. Nature 266: 730-732.

Robbe D, Alonso G, Duchamp F, Bockaert J, Manzoni OJ (2001). Localization and mechanisms of action of cannabinoid receptors at the glutamatergic synapses of the mouse nucleus accumbens. J Neurosci 21: 109-116.

Robbe D, Kopf M, Remaury A, Bockaert J, Manzoni OJ (2002). Endogenous cannabinoids mediate long-term synaptic depression in the nucleus accumbens. Proc Natl Acad Sci USA 99: 8384-8388.

Rodgers RJ, Evans PM, Murphy A (2005). Anxiogenic profile of AM-251, a selective cannabinoid CB1 receptor antagonist, in plus-maze-naive and plus-maze-experienced mice. Behav Pharmacol 16: 405-413.

Rossi S, De Chiara V, Musella A, Kusayanagi H, Mataluni G, Bernardi G et al (2008). Chronic psychoemotional stress impairs cannabinoid-receptor-mediated control of GABA transmission in the striatum. J Neurosci 28: 7284-7292.

Samat A, Tomlinson B, Taheri S, Thomas GN (2008). Rimonabant for the treatment of obesity. Recent Pat Cardiovasc Drug Discov 3: 187-193.

Santarelli L, Saxe M, Gross C, Surget A, Battaglia F, Dulawa S et al (2003). Requirement of hippocampal neurogenesis for the behavioral effects of antidepressants. Science 301: 805-809.

Schlaepfer TE, Cohen MX, Frick C, Kosel M, Brodesser D, Axmacher $\mathrm{N}$ et al (2008). Deep brain stimulation to reward circuitry alleviates anhedonia in refractory major depression. Neuropsychopharmacology 33: 368-377.

Shirayama Y, Ishida H, Iwata M, Hazama GI, Kawahara R, Duman RS (2004). Stress increases dynorphin immunoreactivity in limbic brain regions and dynorphin antagonism produces antidepressant-like effects. J Neurochem 90: 1258-1268.

Valjent E, Mitchell JM, Besson MJ, Caboche J, Maldonado R (2002). Behavioural and biochemical evidence for interactions between Delta 9-tetrahydrocannabinol and nicotine. Br J Pharmacol 135: 564-578.

Varma N, Carlson GC, Ledent C, Alger BE (2001). Metabotropic glutamate receptors drive the endocannabinoid system in hippocampus. J Neurosci 21: RC188.

Wilkinson MB, Xiao G, Kumar A, LaPlant Q, Renthal W, Sikder D et al (2009). Imipramine treatment and resiliency exhibit similar chromatin regulation in the mouse nucleus accumbens in depression models. J Neurosci 29: 7820-7832.

Willner P (1997). Validity, reliability and utility of the chronic mild stress model of depression: a 10-year review and evaluation. Psychopharmacology (Berl) 134: 319-329.

Willner P (2005). Chronic mild stress (CMS) revisited: consistency and behavioural-neurobiological concordance in the effects of CMS. Neuropsychobiology 52: 90-110.

Willner P, Towell A, Sampson D, Sophokleous S, Muscat R (1987). Reduction of sucrose preference by chronic unpredictable mild stress, and its restoration by a tricyclic antidepressant. Psychopharmacology (Berl) 93: 358-364.

Wilson RI, Nicoll RA (2001). Endogenous cannabinoids mediate retrograde signalling at hippocampal synapses. Nature 410: 588-592.

Zhou FM, Wilson CJ, Dani JA (2002). Cholinergic interneuron characteristics and nicotinic properties in the striatum. J Neurobiol 53: 590-605.

Supplementary Information accompanies the paper on the Neuropsychopharmacology website (http://www.nature.com/npp) 